\title{
HUBUNGAN KOMUNIKASI TERAPEUTIK PERAWAT DENGAN TINGKAT KECEMASAN KELUARGA PASIEN YANG DIRAWAT DI RUANGAN HCU RSU SELE BE SOLU KOTA SORONG
}

\author{
Maria Loihala \\ Politeknik Kesehatan Kemenkes Sorong \\ Email: pabar_merlo@yahoo.co.id
}

\begin{abstract}
Relationship of Therapeutic Communication Nurse with Family Anxiety Levels of Patients who were Treated in HCU room, RSU Sele Be Solu Sorong. Patient and family anxiety caused by fear of death, the failure medication complications and cost issues. Communication were not going established between nurses and family members will lead anxiety of family members who were waiting for patients in critical care. For family members, the missing information could resulted in higher anxiety. The aim of study was to determine the relationship therapeutic communication nurse with family anxiety levels of patients were treated in the HCU room, RSU Sele Be Solu Sorong. This study was correlational research design. Total sample were 30 respondents. Data were analyzed by univariate and bivariate. Results showed $p$ value $=0.001 \leq$ $\alpha=0.05$ then Ho was rejected. It can be concluded that therapeutic communication nurse related with the family anxiety levels.
\end{abstract}

Keywords: Communication teraupetik, Nurse, Anxiety

\begin{abstract}
Abstrak: Hubungan Komunikasi Terapeutik Perawat dengan Tingkat Kecemasan Keluarga Pasien yang Dirawat di Ruangan HCU RSU Sele Be Solu Kota Sorong. Kecemasan pasien dan keluarga diakibatkan oleh ketakutan akan kematian, ketidakberhasilan medikasi komplikasi yang terjadi dan masalah biaya. Komunikasi yang dibangun antara perawat dengan anggota keluarga tidak berjalan dengan baik akan menjadikan timbulnya rasa cemas anggota keluarga yang sedang menunggu pasien dalam perawatan kritis. Bagi anggota keluarga, informasi yang kurang mengakibatkan rasa cemas semakin tinggi. Tujuan Penelitian adalah mengetahui hubungan komunikasi terpeutik perawat dengan tingkat kecemasan keluarga yang dirawat di ruangan HCU RSU Sele Be Solu Kota Sorong. Penelitian dengan menggunakan desain penelitian korelasional. Sampel 30 responden. Analisa Data secara univariat dan bivariat. Hasil Penelitian $p$-value $=0.001 \leq$ $\alpha=0.05$ maka Ho ditolak, sehingga disimpulkan bahwa terdapat hubungan antara komunikasi teraupetik perawat dengan tingkat kecemasan keluarga yang dirawat di ruangan HCU RSU Sele Be Solu Kota Sorong.
\end{abstract}

Kata Kunci: Komunikasi Teraupetik, Perawat, Kecemasan

Ansietas atau perasaan cemas akan lebih jelas ditemukan pada pasien dan keluarga pasien yang masuk rumah sakit dalam ruangan intensif. Kecemasan pada pasien dan keluarga sering diakibatkan oleh ketakutan akan kematian, ketidakberhasilan medikasi komplikasi yang terjadi dan masalah biaya (Ganda, 2009).

Komunikasi merupakan alat penghubung dalam bersosial. Sehingga ilmu komunikasi sekarang sangat berkembang pesat. Salah satu kajian ilmu komunikasi ialah komunikasi kesehatan, yang dimana selalu dilakukan saat berhubungan dengan pasien, keluarga dan tenaga kesehatan lainnya (Setiawati, 2007).
Hasil penelitian Vivin Sulastri, (2009) menunjukkan adanya hubungan komunikasi perawat dengan anggota keluarga terhadap kecemasan keluarga pada pasien yang dirawat di unit perawatan kritis (ICU) di RSUD Dr. Moewardi Surakarta. Adanya hubungan dapat diartikan bahwa komunikasi yang dibangun antara perawat dengan anggota keluarga tidak berjalan dengan baik menjadikan timbulnya rasa cemas anggota keluarga yang sedang menunggu pasien dalam perawatan kritis. Bagi anggota keluarga, informasi yang kurang mengakibatkan rasa cemas semakin tinggi, namun dari 30 responden, sebanyak $66,7 \%$ mengalami kecemasan sedang. 
Dari hasil pengamatan penulis di Ruangan HCU RSU Sele Be Solu Kota Sorong kecenderungan yang terjadi yaitu nampak pada hubungan interpersonal perawat dengan pasien dan keluarganya ditunjukkan dengan komunikasi antara perawat yang sering tidak terapeutik saat berinteraksi dengan pasien dan keluarganya, ada beberapa keluhan pasien dan keluarganya terhadap pelayanan yang diberikan yang seharusnya bisa diatasi dengan komunikasi dari perawat.

Banyak faktor penyebab terjadinya kecemasan atau ansietas dalam diri pasien dan keluarganya selama pasien di rumah sakit, salah satunya adalah faktor komunikasi terapeutik perawat. Keluarga akan mengalami ansietas dan disorganisasi perasaan ketika anggota keluarganya mengalami sakit yang harus dirawat di rumah sakit dan ini akan lebih jelas ditemukan di unit perawatan kritis. Pasien yang dirawat dalam Critical Care Unit tidak hanya membutuhkan tehnologi dan terapi tapi juga memerlukan perawatan humanistik dari keluarganya (Rusmini, 2006).

Pada umumnya pasien yang datang di unit perawatan kritis ini adalah dalam keadaan mendadak dan tidak direncanakan, hal ini yang menyebabkan keluarga dari pasien datang dengan wajah yang sarat dengan bermacam-macam stressor yaitu ketakutan akan kematian, ketidakpastian hasil, perubahan pola, kekhawatiran akan biaya perawatan, situasi dan keputusan antara hidup dan mati, rutinitas yang tidak beraturan, ketidak berdayaan untuk tetap atau selalu berada disamping orang yang disayangi sehubungan dengan peraturan kunjungan yang ketat, tidak terbiasa dengan perlengkapan atau lingkungan di unit perawatan kritis, personel atau staf di ruang perawatan, dan rutinitas ruangan. Semua stressor ini menyebabkan keluarga jatuh pada kondisi krisis dimana koping mekanisme yang digunakan menjadi tidak efektif dan perasaan menyerah atau apatis dan kecemasan akan mendominasi perilaku keluarga. Pada saat demikian perawat kurang atau tidak dapat melaksanakan komunikasi terapeutik yang efektif sehingga keluarga akan terus terpuruk dalam situasi yang demikian dan pada akhirnya asuhan keperawatan yang kita berikan secara komperhensif dan holistik tidak akan tercapai dengan baik (Ganda, 2009).

Menurut data dari Ruangan HCU RSU Sele Be Solu Kota Sorong bahwa pasien yang di rawat pada tahun 2013 berjumlah 301 atau ratarata perbulan 25 pasien dan tahun 2014 pasien yang di rawat berjumlah 360 atau rata-rata perbulan 30 pasien. Sementara jumlah perawat yang memberikan pelayanan keperawatan di ruangan HCU RSU Sele Be Solu Kota Sorong sebanyak 12 perawat.

Berdasarkan fenomena di atas, maka penulis tertarik untuk meneliti hubungan komunikasi terapeutik perawat dengan tingkat kecemasan keluarga yang dirawat di ruangan HCU RSU Sele Be Solu Kota Sorong.

\section{METODE PENELITIAN}

Jenis penelitian ini adalah penelitian kuantitatif dengan menggunakan desain penelitian korelasional, dimana dalam penelitian ini mengkaji hubungan antar variabel (Nursalam, 2008).

Populasi dan sampel dalam penelitian ini adalah keluarga pasien yang dirawat selama satu bulan yang berjumlah 30 responden, dengan teknik sampling accidental.

Teknik pengumpulan data yang digunakan dalam penelitian ini dengan menggunakan kuesioner yang meliputi kuesioner komunikasi teraupetik yang terdiri dari 14 pernyataan dan kuesioner kecemasan terdiri dari 10 pertanyaan.

\section{HASIL}

Tabel 1. Distribusi Menurut Karakteristik Sampel

\begin{tabular}{lrr}
\hline Variabel & Jumlah & $\mathbf{( \% )}$ \\
\hline Jenis Kelamin & & \\
\hline Laki-laki & 8 & 26,7 \\
Perempuan & 22 & 73,3 \\
\hline Pendidikan & & \\
\hline SD & 1 & 3,3 \\
SMP & 0 & 0 \\
SMA/SMK & 20 & 66,7 \\
D.III & 6 & 20 \\
S1 & 3 & 10 \\
\hline Umur & & \\
\hline <25 tahun & 3 & 10 \\
25-30 tahun & 8 & 26,7 \\
$>30$ tahun & 19 & 63,3 \\
\hline Pekerjaan & & \\
\hline Bekerja & 16 & 53,3 \\
Tidak bekerja & 14 & 46,7 \\
\hline
\end{tabular}


Tabel 2. Distribusi Menurut Komunikasi Terapeutik dan Kecemasan

\begin{tabular}{lrr}
\hline Variabel & Jumlah & $\mathbf{( \% )}$ \\
\hline $\begin{array}{l}\text { Komunikasi } \\
\text { Teraupetik }\end{array}$ & & \\
\hline Tidak berhasil & 16 & 53,3 \\
Berhasil & 14 & 46,7 \\
\hline Kecenasa & &
\end{tabular}

\section{Kecemasan}

\begin{tabular}{lrl} 
Ringan & 5 & 16,7 \\
Sedang & 7 & 23,3 \\
Berat & 18 & 60,0 \\
\hline
\end{tabular}

Sumber: data primer 2015

Tabel 1 menunjukkan karakteristik Sampel diruangan HCU RSU Sele Be Solu Kota Sorong. Dari 30 responden, responden yang paling banyak berjenis kelamin perempuan yaitu 22 (73.3\%) di bandingkan dengan jenis kelamin laki-laki yaitu 8 responden $(26,7 \%)$. Berdasarkan pendidikan, responden yang berpendidikan SMA/SMK lebih besar pada responden yaitu 20 $(66,7 \%)$ yang berpendidikan DIII yaitu $6(20 \%)$ dibandingkan dengan responden yang berpendidikan S1 yaitu 3 (10\%), berpendidikan SD yaitu $1(3,3 \%)$ dan responden SMP $0(0 \%)$. Berdasarkan umur, responden yang berumur $>30$ tahun yaitu 19 (63,3\%), yang berumur 25-30 tahun yaitu $8(26,7 \%)$ dan yang berumur $<25$ tahun yaitu $3(10 \%)$. Berdasarkan komunikasi terapeutik, responden yang menggunakan komunikasi teraupetik tidak berhasil lebih besar responden yaitu $16(53,3 \%)$ dibandingkan dengan responden yang menggunakan komunikasi terapeutik berhasil yaitu $14(46,7 \%)$.

Berdasarkan kecemasan, responden yang mengalami tingkat kecemasan berat yaitu 18 $(60,0 \%)$ lebih besar dibandingkan dengan responden yang mengalami tingkat kecemasan sedang yaitu 7 responden $(23,3 \%)$ dan ringan 5 responden $(16,7 \%)$.

Berdasarkan hasil analisis bivariat menunjukkan bahwa dari 30 responden, komunikasi teraupetik tidak berhasil dengan kecemasan berat lebih besar $(68,8 \%)$ daripada kecemasan sedang $(18,8 \%)$ dan kecemasan ringan (12,5\%). Sedangkan komunikasi teraupetik berhasil dengan kecemasan berat lebih besar $(50 \%)$ dari pada kecemasan sedang $(28,6 \%)$ dan kecemasan ringan $(21,4 \%)$. Hasil uji statistik dengan menggunakan chi-square diperoleh nilai $p$-value $=0,001 \leq \alpha$ (alpha) 0,05 dengan demikian Ho ditolak yang berarti ada hubungan komunikasi terapeutik perawat dengan tingkat kecemasan keluarga yang dirawat di ruangan HCU RSU Sele Be Solu Kota Sorong.
Tabel 3. Tabel Silang Hubungan Komunikasi Terapeutik Perawat dengan Tingkat Kecemasan Keluarga

\begin{tabular}{|c|c|c|c|c|c|c|c|}
\hline \multirow{3}{*}{$\begin{array}{l}\text { Komunikasi } \\
\text { Teraupetik } \\
\text { Perawat }\end{array}$} & \multicolumn{5}{|c|}{ Kecemasan } & \multirow{2}{*}{\multicolumn{2}{|c|}{ Total }} \\
\hline & Ringan & \multicolumn{2}{|c|}{ Sedang } & \multicolumn{2}{|c|}{ Berat } & & \\
\hline & f $\%$ & $\mathbf{f}$ & $\%$ & f & $\%$ & $\mathbf{f}$ & $\%$ \\
\hline $\begin{array}{l}\text { Tidak } \\
\text { berhasil }\end{array}$ & 12,5 & 3 & 18,8 & 11 & 68,8 & 16 & 100 \\
\hline Berhasil & 21,4 & 4 & 28,6 & 7 & 50,0 & 14 & 100 \\
\hline Total & 5 & 7 & & 18 & & 30 & 100 \\
\hline
\end{tabular}

Sumber : Data Primer 2015

\section{PEMBAHASAN}

\section{a. Komunikasi Teraupetik Perawat}

Hasil penelitian menunjukkan bahwa responden yang menggunakan komunikasi teraupetik tidak berhasil lebih besar yaitu 16 $(53,3 \%)$ dibandingkan dengan responden yang menggunakan komunikasi terapeutik berhasil yaitu 14 (46,7\%). Namun penelitian Sri Asih Rusmini, (2012) di RSU Doris Sylvanus Palangkaraya didapatkan bahwa perilaku perawat khususnya dalam berkomunikasi kurang baik. Sementara itu penelitian yang dilakukan $\mathrm{Hj}$. Indirawaty di RSU Haji Sukolilo Surabaya bahwa kepuasan pasien terhadap komunikasi perawat $(54,2 \%)$ tidak puas, $(16,7 \%)$ cukup puas dan $(29,2 \%)$ sangat puas.

Menurut Setianti (2007), mengatakan komunikasi merupakan alat penghubung dalam bersosial. Salah satu kajian ilmu komunikasi ialah komunikasi kesehatan, yang dimana selalu dilakukan saat berhubungan dengan pasien, keluarga dan tenaga kesehatan lainnya. Komunikasi yang terjalin antara perawat dan pasien disebut sebagai komunikasi teraupetik. Komunikasi terapeutik adalah komunikasi yang dilakukan atau dirancang untuk tujuan terapi. Seorang penolong atau perawat dapat membantu pasien mengatasi masalah yang dihadapinya melalui komunikasi (Suryani, 2005). Dikatakan lagi oleh Mundakir (2006), bahwa komunikasi terapeutik adalah komunikasi yang direncanakan secara sadar, bertujuan dan kegiatannya dipusatkan untuk kesembuhan. Selanjutnya Siti Fatmawati (2010) mengatakan pada dasarnya komunikasi terapeutik merupakan komunikasi professional yang mengarah pada tujuan yaitu penyembuhan pasien.

Sementara Mubarak \& Chatain, (2009) menyatakan bahwa komunikasi teraupetik memberikan gambaran yang jelas kepada perawat tentang kondisi pasien yang sedang dirawat, mengenai tanda dan gejala yang ditampilkan 
serta keluhan yang dirasakan. Komunikasi teraupetik terjadi apabila didahului hubungan saling percaya antara perawat-pasien.

Menurut asumsi peneliti, keterampilan berkomunikasi harus dimiliki oleh seorang perawat, karena komunikasi merupakan proses yang digunakan untuk mengumpulkan data pengkajian, memberikan pendidikan atau informasi kesehatan dan mempengaruhi pasien untuk mengaplikasikannya dalam hidup, menunjukan kepedulian, memberikan rasa nyaman, menumbuhkan rasa percaya diri dan menghargai nilai-nilai pasien, karena komunikasi efektif merupakan hal penting dalam menciptakan hubungan antara perawat dan pasien.

\section{b. Kecemasan Keluarga}

Hasil penelitian menunjukkan bahwa responden yang mengalami tingkat kecemasan berat yaitu $18(60,0 \%)$ lebih besar dibandingkan dengan responden yang mengalami tingkat kecemasan sedang yaitu 7 responden $(23,3 \%)$ dan ringan 5 responden $(16,7 \%)$. Namun menurut penelitian yang dilakukan Prihatiningsih (2012) menunjukkan bahwa tingkat kecemasan keluarga pasien di Ruang Melati RSUD Kebumen mayoritas berkategori sedang $(62,7 \%)$.

Kecemasan disebabkan faktor patofisiologis maupun faktor situasional (Sutrimo, 2012). Penyebab kecemasan tidak spesifik bahkan tidak diketahui oleh individu. Perasaan cemas diekspresikan secara langsung melalui perubahan fisiologis dan perilaku, dapat juga diekspresikan secara tidak langsung melalui timbulnya gejala dan mekanisme koping sebagai upaya melawan kecemasan (Stuart 2007).

Kecemasan disebabkan faktor patofisiologis maupun faktor situasional (Sutrimo, 2012). Penyebab kecemasan tidak spesifik bahkan tidak diketahui oleh individu. Perasaan cemas diekspresikan secara langsung melalui perubahan fisiologis dan perilaku, dapat juga diekspresikan secara tidak langsung melalui timbulnya gejala dan mekanisme koping sebagai upaya melawan kecemasan (Stuart 2007).

Menurut asumsi penulis, kecemasan merupakan perasaan tidak menentu yang umumnya tidak menyenangkan. Kecemasan dialami oleh keluarga pasien dikarenakan ketakutan akan penyakit yang diderita oleh pasien. Dengan komunikasi terapeutik yang efektif, maka tingkat kecemasan juga akan berkurang.

\section{c. Hubungan Komunikasi Terapeutik dengan Tingkat Kecemasan}

Komunikasi teraupetik memberikan gambaran yang jelas kepada perawat tentang kondisi pasien yang sedang dirawat, mengenai tanda dan gejala yang ditampilkan serta keluhan yang dirasakan. Komunikasi teraupetik terjadi apabila didahului hubungan saling percaya antara perawat-pasien.

Berdasarkan uji statistik didapatkan bahwa $p=0,001 \unlhd 0,05$ ini menunjukan bahwa ada hubungan antara komunikasi terapeutik dengan tingkat kecemasan keluarga yang dirawat di ruangan HCU RSU Sele Be Solu Kota Sorong. Penelitian ini sama dengan penelitian Vivin Sulastri, (2009) yang menunjukkan bahwa adanya hubungan komunikasi perawat dengan anggota keluarga terhadap kecemasan keluarga pada pasien yang dirawat di unit perawatan kritis (ICU) di RSUD Dr. Moewardi Surakarta. Penelitian Rusmini, (2006) tentang hubungan komunikasi terapeutik dengan kecemasan keluarga di RSU Doris Sylvanus Palangkaraya didapatkan bahwa perilaku perawat khususnya dalam berkomunikasi kurang baik.

Adanya hubungan dapat diartikan bahwa komunikasi yang dibangun antara perawat dengan anggota keluarga tidak berjalan dengan baik menjadikan timbulnya rasa cemas anggota keluarga yang sedang menunggu pasien dalam perawatan kritis.

Menurut Ganda (2009) bahwa Ansietas atau perasaan cemas akan lebih jelas ditemukan pada pasien dan keluarga pasien yang masuk rumah sakit dalam ruangan intensif. Kecemasan pada pasien dan keluarga sering diakibatkan oleh ketakutan akan kematian, ketidakberhasilan medikasi komplikasi yang terjadi dan masalah biaya. Sedangkan Stuart (2007) menjelaskan bahwa kecemasan merupakan emosi subjektif yang membuat individu tidak nyaman, ketakutan yang tidak jelas dan gelisah, dan disertai respon otonom.

Pengalaman cemas setiap individu bervariasi bergantung pada situasi dan hubungan interpersonal. Ada dua faktor presipitasi yang mempengaruhi kecemasan yaitu faktor eksternal dan faktor internal. Faktor internal meliputi pendidikan dimana pendidikan individu berpengaruh terhadap kemampuan berpikir. Semakin tinggi tingkat pendidikan maka individu semakin mudah berpikir rasional dan menangkap informasi baru. Kemampuan analisis akan mempermudah individu dalam menguraikan masalah baru, hal ini sesuai dengan hasil 
penelitian bahwa sebagian besar responden berpendidikan SMA/SMK yaitu $20(66,7 \%)$ yang berpendidikan DIII yaitu 6 (20\%) dibandingkan dengan responden yang berpendidikan $\mathrm{S} 1$ yaitu 3 $(10 \%)$.

Selain faktor pendidikan faktor lainnya adalah jenis kelamin dimana gangguan kecemasan tingkat panik lebih sering dialami wanita daripada pria. Dampak negatif dari kecemasan merupakan rasa khawatir yang berlebihan tentang masalah yang nyata maupun potensial. Keadaan cemas akan membuat individu menghabiskan tenaganya, menimbulkan rasa gelisah, dan menghambat individu melakukan fungsinya dengan adekuat dalam situasi interpersonal maupun hubungan sosial, hal ini sama dengan hasil penelitian bahwa menunjukkan bahwa responden sebagian besar responden jenis kelamin perempuan yaitu 22 responden $(73,3 \%)$. Faktor selanjutnya adalah usia. Usia muda lebih mudah cemas dibandingkan individu dengan usia yang lebih tua, hal ini berbeda dengan hasil penelitian bahwa sebagian besar responden berumur $>30$ tahun pada responden yaitu 19 (63,3\%).

Teori konflik memandang cemas sebagai pertentangan antara dua kepentingan yang berlawanan. Kecemasan terjadi karena adanya hubungan timbal balik antara konflik dan kecemasan. Konflik menimbulkan kecemasan, dan cemas menimbulkan perasaan tak berdaya, yang pada gilirannya meningkatkan konflik yang dirasakan. Selain itu teori kajian keluarga mengatakan bahwa Kajian keluarga menunjukkan bahwa gangguan cemas terjadi didalam keluarga. Gangguan kecemasan juga tumpang tindih antara gangguan kecemasan dan depresi (Stuar, 2007).

Smet (1994) menjelaskan bahwa perawat jarang melakukan komunikasi interpersonal dengan pasien, dan dikemukakan oleh Ellis (2009) bahwa hal tersebut disebabkan oleh (1) kurangnya kesadaran diri perawat, (2) kurangnya pelatihan keterampilan interpersonal yang

\section{DAFTAR PUSTAKA}

Abraham. 1997. Psikologi Sosial Untuk Perawat. Jakarta:

EGC. http://ris.uksw.edu/download/jurnal/kode/J 01145. (Akses 12 Mei 2015)

Ellis. 2009. Komunikasi Interpersonal dalam Keperawatan Teori dan Praktik. Alih bahasa: Susi Purwoko; Editor: Setiawan. Jakarta: EGC. sistematik, (3) kurangnya kerangka konseptual dan, (4) kurangnya kejelasan tujuan.

Menurut Abraham (1997) bahwa ketidakmampuan perawat dalam menerapkan komunikasi terapeutik akan berdampak negatif bagi mutu pelayanan keperawatan di rumah sakit serta akan menimbulkan ketidakpuasan pasien terhadap pelayanan keperawatan yang diberikan. Pasien yang dirawat baik di ruang bedah, ruang penyakit dalam maupun ruangan anak mempunyai rasa kekuatiran akibat proses hospitalisasi. Jika kekuatiran tidak dikomunikasikan maka akan menganggu hubungan perawat-pasien, serta akan dapat meningkatkan kecemasan pasien. Pasien dalam keadaan cemas, lebih cenderung mengalami sensasi jasmaniah dan tanda-tanda terancam. Kecemasan bila berlanjut dapat mempengaruhi status kesehatan serta dapat mengubah prosedur diagnosa yang telah ditentukan. Untuk dapat meningkatkan kepercayaan diri pasien dalam menghadapi suatu tindakan perawatan salah satunya maka komunikasi teraupetik perawatpasien perlu dibangun agar, pasien dapat memilih alternatif coping yang positif bagi dirinya (Stuart, 2007).

Menurut asumsi penulis, Perawat memegang penting dalam layanan kesehatan kepada pasien dan keluarga. Komunikasi merupakan alat penghubungnya. Upaya penurunan kecemasan dapat dilakukan dengan menjalin hubungan komunikasi yang baik, dalam hal ini komunikasi terapeutik.

\section{SIMPULAN}

Berdasarakan hasil penelitian, maka dapat disimpulkan bahwa ada hubungan komunikasi terapeutik perawat dengan tingkat kecemasan keluarga yang dirawat di ruangan HCU RSU Sele Be Solu Kota Sorong.

Fatmawati. 2010. Komunikasi Keperawatan Plus materi Komunikasi Terapeutik. Yogjakarta: Medical Book.

Ganda. 2009. Petunjuk Praktis Cara Mahasiswa Belajar di Perguruan Tinggi [online].ed.Canada: Thomson. http:// books.google. co.id/books?id= atD2wBku45YC\&pg=PA5\&dq=mahasisw $\mathrm{a}+$ adalah\&hl=id\&ei=v9yrTom4IM3 wrQf0 
-5 TjDA\&sa $=$ X\&oi $=$ book_result\&c $\mathrm{t}=$ result\&resnum $=$ $6 \& v e d=0 C E I Q 6 A E w B Q \# v=$ on epage $\& \mathrm{q}=$ mandiri\& $\mathrm{f}=$ fals.

Jakarta: Grasindo. (Akses 12 Mei 2015)

Nursalam. 2008. Konsep dan Penerapan Metodologi Penelitian Ilmu Keperawatan. Jakarta: Salemba Medika.

Mubarak, W.I. Chayatin, N. 2009. Ilmu Kesehatan Masyarakat Teori dan Aplikasi. Jakarta: Salemba Medika. http://digilib.unimus.ac.id/files/disk1/119/j tptunimus-gdl-caturhardi-5908-4-daftarpa.pdf (Akses 4 April 2015)

Mundakir. 2006. Komunikasi Keperawatan Aplikasi Dalam Pelayanan. Yogyakarta: Graha Ilmu. http://digilib.unimus.ac.id/files/disk1/161/j tptunimus-gdl-tamioksani-8014-5-daftarpp.pdf (Akses 2 Juni 2015)

Prihatiningsih, D. 2012. Hubungan Komunikasi Terapeutik Dengan Tingkat Kecemasan Keluarga Pasien di Ruang Melati RSUD Kebumen. STIKES Muhammadiyah Gombong. http://uda.ac.id/jurnal/files/Ganda_FIK.pdf

Rusmini. 2006. Perkembangan anak dan remaja. Jakarta: PT. Rineka Cipta. http://digilib.unimus.ac.id/files/disk1/134/j tptunimus-gdl-odefandier-6682-5-daftarp3.pdf (Akses 4 April 2015)

Setianti. 2007. Komunikasi Teraputik Antara Perawat dan Pasien. http://pustaka.unpad.ac.id/wpcontent/uploads/2009/01/komunikasi_terap eutik.pdf. (Akses 2 Juni 2015)

Setiawati, A., Suyatna, F.D., dan Gan, Sulistia. 2007. Farmakologi Dan Terapi. Jakarta: Departemen Farmakologi dan Terapeutik
FKUI.

http://repository.usu.ac.id/bitstream/12345 6789/25624/2/Reference.pdf (Akses 2 Juni 2015)

Smet. 1994. Psikologi Kesehatan. Jakarta. Gramedia Widiasarana Indonesia. http://ris.uksw.edu/download/jurnal/kode/J 01145. (Akses 12 Mei 2015)

Stuart. 2007. Buku Saku Keperawatan Jiwa. Jakarta: EGC. http:// repository.usu.ac.id /bitstream/123456789/34273/1/Reference. pdf (Akses 17 Februari 2015)

Sugiyono. 2004. Metode Penelitian Administrasi. Bandung: Penerbit Alphabet. http://repository.usu.ac.id/bitstream/12345 6789/34273/1/Reference.pdfC (Akses 2 Juni 2015)

Sutrimo. A 2012. Pengaruh Guided Imagery and Music (GIM) terhadap kecemasan pasien pre operasi section caesarea di RSUD Banyumas. S1 Keperawatan, FK Universitas Jenderal Soedirman Purwokerto.

http://digilib.stikeskusumahusada.ac.id/file s/disk1/13/01-gdl-nurkasanas-617-1s10030n-a.pdf (Akses 2 Juni 2015)

Suryani. 2005. Komunikasi Terapeutik: Teori dan Praktik. Buku Kedokteran. Jakarta: EGC.

Vivin Sulastri. 2009. Hubungan Komunikasi Terapeutik Perawat dengan Anggota Keluarga Terhadap Tingkat Kecemasan Keluarga pada Pasien yang Dirawatn di Unit Perawatan Kritis di RSUD Dr. Moewardi Surakarta. https:// publikasiilmiah.ums. ac.id/bitstream/ handle/11617/3629/VIVIN\%20CANDRA $\%$ 20IKAWAT-SULASTRI\%

20Fix.pdf?sequence $=1$ (Akses 2 Juni 2015). 